\title{
Cement leakage causes potential thermal injury in vertebroplasty
}

Po-Liang Lai ${ }^{1,2+}$, Ching-Lung Tai ${ }^{3^{*}+}$, Lih-Huei Chen ${ }^{1}$ and Nai-Yuan Nien ${ }^{3}$

\begin{abstract}
Background: Percutaneous vertebroplasty by injecting PMMA bone cement into the fractured vertebrae has been widely accepted in treatment of spinal compression fracture. However, the exothermic polymerization of bone cement may cause osseous or neural tissue injury. This study is thus designed to evaluate the potential risk of thermal damage in percutaneous vertebroplasty.

Method: Twelve porcine vertebrae were immersed in $37^{\circ} \mathrm{C}$ saline for the experiment. In the first stage of the study, vertebroplasty without cement leakage (control group, $\mathrm{n}=6$ ) was simulated. The anterior cortex, foramen, posterior cortex and the center of the vertebral body were selected for temperature measurement. Parameters including peak temperature and duration above $45^{\circ} \mathrm{C}$ were recorded. In the second stage, a model $(n=6)$ simulating bone cement leaking into the spinal canal was designed. The methods for temperature measurement were identical to those used in the first stage.

Results: In Stage 1 of the study (vertebroplasty of the porcine vertebral body in the absence of cement leakage), the average maximal temperature at the anterior cortex was $42.4 \pm 2.2^{\circ} \mathrm{C}$; at the neural foramen $39.5 \pm 2.1^{\circ} \mathrm{C}$; at the posterior cortex $40.0 \pm 2.5^{\circ} \mathrm{C}$ and at the vertebral center, $68.1 \pm 3.4^{\circ} \mathrm{C}$. The average time interval above $45^{\circ} \mathrm{C}$ was 0 seconds at the anterior cortex; at the neural foramen, 0 seconds; at the posterior cortex, 0 seconds and at the vertebral center, 223 seconds. Thus, except at the core of the bone cement, temperatures around the vertebral body did not exceed $45^{\circ} \mathrm{C}$. In Stage 2 of the study (cement leakage model), the average maximal temperature at the anterior cortex was $42.7 \pm 2.4^{\circ} \mathrm{C}$; at the neural foramen, $41.1 \pm 0.4^{\circ} \mathrm{C}$; at the posterior cortex, $59.1 \pm 7.6^{\circ} \mathrm{C}$ and at the vertebral center, $77.3 \pm 5.7^{\circ} \mathrm{C}$. The average time interval above $45^{\circ} \mathrm{C}$ at the anterior cortex was 0 seconds; at the neural foramen, 0 seconds; at the posterior cortex, 329.3 seconds and at the vertebral center, 393.2 seconds. Based on these results, temperatures exceeded $45^{\circ} \mathrm{C}$ at the posterior cortex and at the vertebral center.

Conclusions: The results indicated that, for bone cement confined within the vertebra, curing temperatures do not directly cause thermal injury to the nearby soft tissue. If bone cement leaks into the spinal canal, the exothermic reaction at the posterior cortex might result in thermal injury to the neural tissue.
\end{abstract}

\section{Background}

Osteoporotic vertebral fractures are a major health care problem; they cause severe, debilitating back pain and consequent reduced physical function and have an enormous impact on quality of life [1]. Conservative management, which may include analgesics, bed rest, use of a brace, and rehabilitation, is indicated in patients who do not have neurological impairment. Surgery is

\footnotetext{
* Correspondence: taicl@mail.cgu.edu.tw

† Contributed equally

${ }^{3}$ Graduate Institute of Medical Mechatronics, Department of Mechanical

Engineering, Chang Gung University, Taoyuan, Taiwan

Full list of author information is available at the end of the article
}

indicated in patients who have symptoms that are refractory to conservative treatment modalities and in patients who have spinal instability and progressive neurological deficit. Open surgery is risky in older patients because of the poor quality of osteoporotic bone and co-morbidities.

Vertebroplasty, the percutaneous injection of polymethylmethacrylate (PMMA) into the fractured vertebral body, has been widely accepted as a treatment for painful osteoporotic vertebral fractures. Several studies suggest that immediate and sustained pain relief and restoration of vertebral body height are achieved through this procedure [2-4]. Vertebroplasty achieves its

\section{Biomed Central}


analgesic effect by preventing motion of the fractured fragments and by stabilizing the vertebral bodies.

PMMA is biocompatible and nonabsorbable. Because PMMA cement cures rapidly, reconstructions are mechanically stable within a few hours of surgery. However, the use of PMMA in vertebral augmentation is also associated with complications and risks. Possible cytotoxic and hypotensive effects of the PMMA monomer have been studied [5]. A possible cause of neurological deficit after intraspinal bone cement leakage is mechanical compression of the spinal cord [6-8]. Some authors have hypothesized that thermal injury could occur as a result of cement leakage occurred during vertebroplasty. It has been shown that the heat that develops during PMMA curing can damage not only the surrounding body tissue but also adjacent soft tissue, including the spinal cord, nerve roots, major vessels, and even lung parenchyma in the thoracic spine [9]. Wilkes reported cases of paraplegia that they attributed to thermal injury after PMMA injection into a vertebral body [10]. Uchiyama reported that protein damage and cell death in an animal model are aggravated when the temperature goes above $45^{\circ} \mathrm{C}$ [11]. However, literature that definitively addresses the effects of thermal damage during vertebroplasty is lacking. The present study was thus designed to illustrate the potential risk of thermal damage in percutaneous vertebroplasty in an in vitro animal model.

\section{Methods}

In this study, porcine vertebral bodies were used as substitutes for human cadaveric spines. Ethics was approved by the review board of Chang Gung Memorial Hospital. We carried out the experiments in two stages.

\section{Stage 1. Vertebroplasty in porcine vertebral body}

Six fresh vertebral bodies (T10-L1) harvested from fresh porcine spines were used. The vertebrae were disarticulated and their discs were excised. In order to standardize the baseline temperature, all specimens were immersed in $37^{\circ} \mathrm{C}$ saline in a water tank (Lipsh, SHANDO Co., USA) 30 minutes before injection of bone cement. Needle thermocouples (SE319, TECPEL Co., Taiwan) were used to record the temperature. The thermocouples were connected to a digital 4-input temperature data logger (Model: DTM-319, TECPEL Co., Taiwan) controlled by a personal computer. The temperature resolution was $0.1^{\circ} \mathrm{C}$. To facilitate the attachment of thermocouples at the designated locations, the cortex of each vertebral body was penetrated using a 20 -gauge needle. Thermocouples were inserted to a depth of $1.0 \mathrm{~mm}$. After injection of PMMA cement, temperature changes at four locations in the vertebral body were measured simultaneously. The anterior thermocouple (1) was attached to the anterior cortex, halfway between the anterior margin of the superior endplate and the inferior endplate, representing the potential thermal effect on the great vessels. The foramen thermocouple (2) was attached to the inferior cortex of the pedicle at the point where the existing nerve root passes; this site was selected in order to determine the risk of thermal damage to the nerve roots. The posterior thermocouple (3) was attached to the posterior cortex, halfway between the posterior margin of the superior endplate and that of the inferior endplate; this site was used to estimate the risk of thermal damage to the spinal cord. The central thermocouple (4) was placed in the center of the cavity in which the PMMA cement was embedded and measured the core temperature of the PMMA cement. The placement of the four thermocouples is shown in Figure 1. Parameters including peak temperature and duration above $45^{\circ} \mathrm{C}$ were recorded.

A cavity was created in each porcine vertebral body by drilling to simulate a bone defect in the vertebral body. The entry point was the center of the superior endplate. The diameter of the drill was $12.7 \mathrm{~mm}$, and the depth of penetration through the superior endplate was 30 $\mathrm{mm}$. By calculation, the cavity volume was $3.8 \mathrm{~mL}$. Each vertebra received $3.8 \mathrm{~mL}$ of PMMA cement (Simplex ${ }^{\circledR}$ P, Stryker Inc., Ireland) embedded in the man-made cavity. The cement was mixed according to the manufacture's guidelines. Temperature changes were measured during the curing of the bone cement. Data were

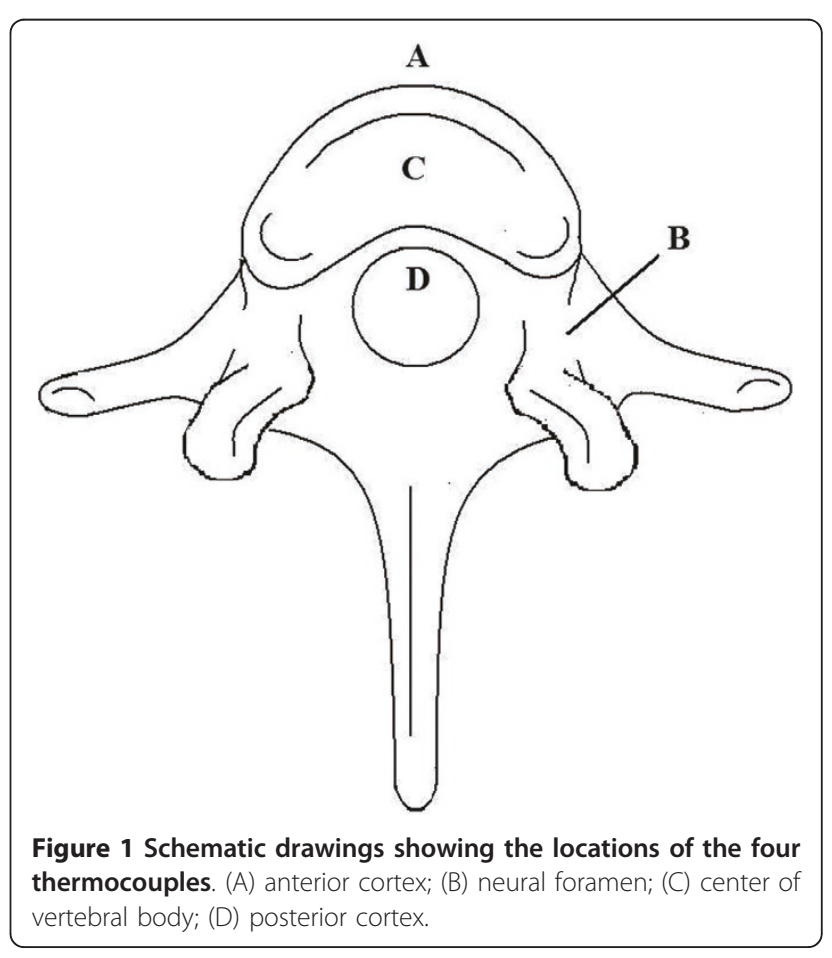


collected at $1 \mathrm{~Hz}$; each specimen was measured for at least 16 minutes.

\section{Stage 2. Bone cement leakage model}

A bone cement leakage model using the porcine spinal vertebrae was designed to simulate vertebroplasty with cement leakage. Another six fresh vertebral bodies (T10-L1) harvested from fresh porcine spines were used. The center point between the bilateral pedicles was designated as the leakage point of the posterior cortex. A 2-mm drill tip was used to penetrate the cortex to create the leakage point. Simplex ${ }^{\circledR} \mathrm{P}$ bone cement was injected into the cavity as in Stage 1. The posterior aspect of the vertebral body was kept in a horizontal position. The bone cement was injected continuously until the leaked bone cement flooded the margin of the vertebral body; the amount of injected bone cement depended on the amount of leaked bone cement. To measure the volume of the leaked bone cement, leaked cement was removed from the spinal canal via osteotomy. The volume of the leaked cement was measured by immersion in a $5-\mathrm{mL}$ syringe containing $3 \mathrm{~mL}$ of water, and the elevated water level was measured. Using this method, we standardized the amount of leaked bone cement for each specimen (Figure 2). Needle thermocouples were connected to the four designated points described in Stage 1, and temperature measurement was carried out in a $37^{\circ} \mathrm{C}$ saline water tank. Parameters including peak temperature, duration above $45^{\circ} \mathrm{C}$ and time required to reach peak temperature, were recorded simultaneously during the entire process of PMMA cement polymerization.

\section{Statistical analysis}

To evaluate the effect of cement leakage on temperature change at specific positions, a two-tailed Student's $t$-test

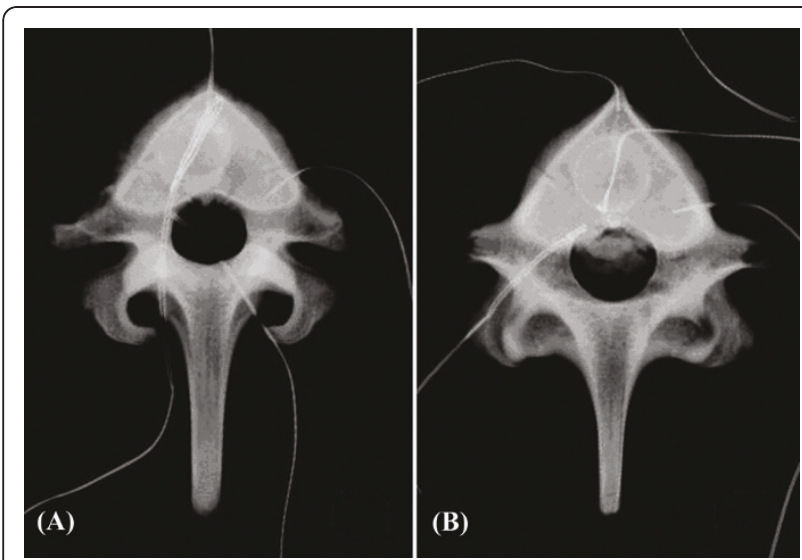

Figure 2 X-ray photographs of porcine vertebra after vertebroplasty show (A) no leakage; (B) cement leakage into the spinal canal. was used to compare the highest temperature at each position between groups (stage 1 and stage 2). Differences were considered significant for $\mathrm{p}<0.05$.

\section{Results}

All the specimens were porcine vertebrae, T10-L2; the average weight was $71.0 \pm 5.1 \mathrm{~g}$, and the mean length, width, and height were $26.1 \pm 1.3 \mathrm{~mm}, 36.7 \pm 1.6 \mathrm{~mm}$ and $37.8 \pm 2.0 \mathrm{~mm}$, respectively.

In Stage 1 of the study (vertebroplasty in the porcine vertebral body), the average maximal temperatures were $42.4 \pm 2.2^{\circ} \mathrm{C}$ at the anterior cortex, $39.5 \pm 2.1^{\circ} \mathrm{C}$ at the neural foramen, $40.0 \pm 2.5^{\circ} \mathrm{C}$ at the posterior cortex and $68.1 \pm 3.4^{\circ} \mathrm{C}$ at the vertebral center (Table 1 ). The average duration of temperature elevation above $45^{\circ} \mathrm{C}$ was 0 seconds at the anterior cortex, 0 seconds at the neural foramen, 0 seconds at the posterior cortex and $223 \mathrm{sec}-$ onds at the vertebral center (Figure 3). Based on the results, temperatures around the vertebral body did not exceed $45^{\circ} \mathrm{C}$ except at the core of the bone cement.

In Stage 2 of the study (cement leakage model), the amount of leaked bone cement within the spinal canal was $1.18 \pm 0.23 \mathrm{~mL}$. The average maximal temperature was $42.7 \pm 2.4^{\circ} \mathrm{C}$ at the anterior cortex; $41.1 \pm 0.4^{\circ} \mathrm{C}$ at the neural foramen, $59.1 \pm 7.6^{\circ} \mathrm{C}$ at the posterior cortex and $77.3 \pm 5.7^{\circ} \mathrm{C}$ at the vertebral center (Table 1). The average duration of temperature elevation above $45^{\circ} \mathrm{C}$ was 0 seconds at the anterior cortex, 0 seconds at the neural foramen, 329.3 seconds at the posterior cortex and 393.2 seconds at the vertebral center (Figure 4). Based on the results, the temperatures exceeded $45^{\circ} \mathrm{C}$ at the posterior cortex and at the vertebral center.

Temperatures at the anterior cortex and the neural foramen did not exceed $45^{\circ} \mathrm{C}$ in vertebroplasty with or without cement leakage. However, at the posterior cortex, the peak temperature and duration above $45^{\circ} \mathrm{C}$ increased in the cement-leakage model. Thus, vertebroplasty with cement leakage resulted in conditions that are potentially thermally damaging to the surrounding soft tissue.

\section{Discussion}

In clinical situations, it is not possible to standardize the amount of bone cement injected into the vertebral body, the distribution of bone cement within the vertebral body, and the distance between the cortex and the bone cement. The energy release by a bolus of cement is proportional to the volume of cement injected $[12,13]$. The distance between cortex and bone cement influences heat dispersion. In the present study, the amount of bone cement, the shape of the cavity and the distance between bone cement and cortex were standardized.

Experiments to study vertebroplasty, including quantitative injection of cement, placing thermocouples at 
Table 1 Highest observed temperatures at four locations within each specimen in Stage 1 (vertebroplasty without cement leakage) and Stage 2 (vertebroplasty with cement leakage) experiments

\begin{tabular}{|c|c|c|c|c|c|c|c|c|}
\hline \multirow[b]{3}{*}{ Specimen } & \multicolumn{8}{|c|}{ Locations of thermocouples } \\
\hline & \multicolumn{2}{|c|}{ Anterior } & \multicolumn{2}{|c|}{ Foramen } & \multicolumn{2}{|c|}{ Posterior } & \multicolumn{2}{|c|}{ Center } \\
\hline & Stage 1 & Stage 2 & Stage 1 & Stage 2 & Stage 1 & Stage 2 & Stage 1 & Stage 2 \\
\hline 1 & 38.4 & 38.3 & 37.1 & 41.2 & 36.9 & 65.8 & 75.0 & 82.4 \\
\hline 2 & 44.6 & 44.3 & 43.4 & 41.1 & 39.6 & 68.4 & 65.8 & 76.1 \\
\hline 3 & 41.8 & 42.1 & 38.7 & 41.0 & 40.0 & 61.8 & 66.6 & 72.9 \\
\hline 4 & 43.8 & 42.8 & 38.9 & 40.4 & 38.8 & 48.5 & 66.5 & 85.5 \\
\hline 5 & 42.0 & 44.3 & 39.7 & 41.2 & 44.6 & 53.9 & 67.7 & 70.5 \\
\hline 6 & 43.7 & 44.4 & 39.4 & 41.8 & 39.8 & 56.3 & 67.2 & 76.6 \\
\hline Avg. & 42.4 & 42.7 & 39.5 & 41.1 & 40.0 & 59.1 & 68.1 & 77.3 \\
\hline SD & 2.2 & 2.4 & 2.1 & 0.4 & 2.5 & 7.6 & 3.4 & 5.7 \\
\hline P-value & \multicolumn{2}{|c|}{0.81} & \multicolumn{2}{|c|}{0.10} & \multicolumn{2}{|c|}{0.0001} & \multicolumn{2}{|c|}{0.007} \\
\hline
\end{tabular}

$\left({ }^{\circ} \mathrm{C}\right)$

designated locations, and deliberately leaking bone cement into the spinal canal, cannot be conducted in humans. However, numerous investigations using animal vertebral bodies as a substitute for cadaveric specimens have shown that animal vertebrae provide a good model for examining the mechanical characteristics and temperature profiles of vertebroplasty in human patients [14-16]. Zhao et al. [14] assessed the effects of surface treatment with a novel injectable strontium-containing bioactive bone cement (SrHAC) for vertebroplasty using porcine vertebrae. Their results revealed that the stiffness of the fractured spine recovered to $82.5 \%$ ( $p<0.01$ ) of the intact condition after cementation with surfacetreated SrHAC. Aeble et al. [15] examined temperature profiles during vertebroplasty in a sheep model. These authors concluded that the spinal cord do not seem to

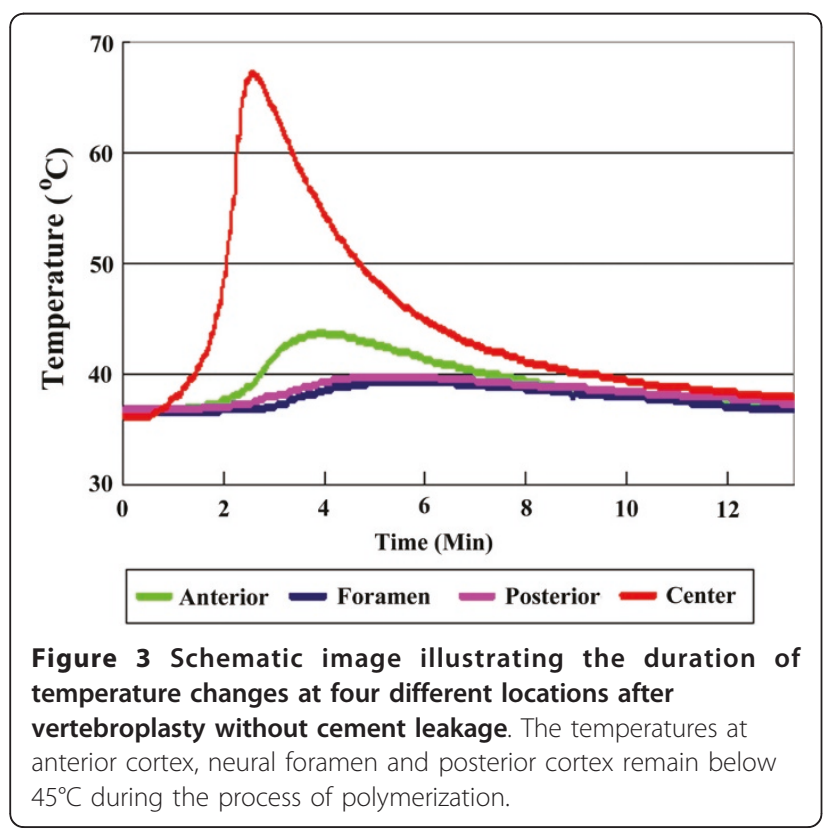

be in danger of thermal damage during vertebroplasty if no leakage. In a recent study, Turner et al. [16] compared the compressive strength of adjacent motion segments and the histological response of vertebral bodies injected with calcium phosphate $(\mathrm{CaP})$ or polymethylmethacrylate (PMMA) in a canine vertebroplasty model. Their results indicated no significant difference in vertebral body height and compressive strength between PMMA and CaP. However, unlike PMMA, CaP underwent resorption and remodeling, with vascular invasion and bone ingrowth.

Thermal damage from the exothermic curing of PMMA has been implicated as a factor in the development of bone necrosis around hip and knee implants. In vertebroplasty, the heat that develops during PMMA cement curing may damage not only the surrounding

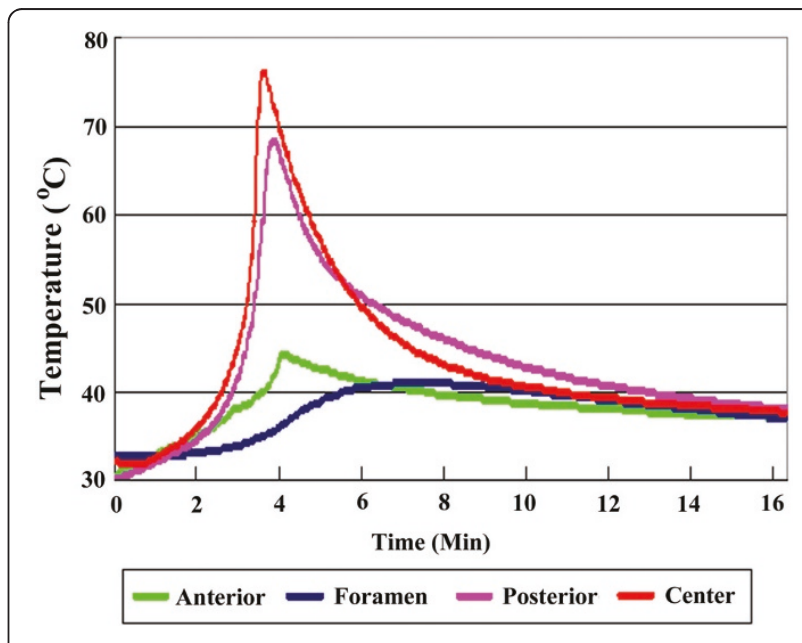

Figure 4 Schematic image illustrating the duration of temperature changes at four different locations after vertebroplasty with cement leakage into the spinal canal. The temperatures at the center of the vertebra and at the posterior cortex exceed $45^{\circ} \mathrm{C}$. 
body tissue but also adjacent soft tissue including the spinal cord, nerve roots, major vessels, and even lung parenchyma in the thoracic spine. Toksvig-Larsen et al. used human cadavers to investigate temperature changes during PMMA cementation of a corpectomy defect and reported temperature increases of $4^{\circ} \mathrm{C}$ to $12^{\circ} \mathrm{C}$ on the external surfaces of the dura [17]. Thermal injury to neural structures is related to the increase in temperature and to the duration of exposure. Hyperthermia led to a dose-dependent decrease in motor and sensory function in a rat sciatic nerve treated in vivo with hyperthermia $\left(43-45^{\circ} \mathrm{C}\right)$ for different times [18]. In an experimental study of spinal cord heating, Uchiyama concluded that, at $45^{\circ} \mathrm{C}$ or above, reduction of amplitude combined with shortened latency of nerve signals occurred [11].

Berman et al. suggested that PMMA bone cement be designed to limit intraoperative temperature maximums to less than $70^{\circ} \mathrm{C}$, because, in a rabbit model, bone necrosis was consistently seen in histological sections of tissues exposed to temperatures greater than or equal to $70^{\circ} \mathrm{C}$ [19]. A sensitive vital microscopic method showed consistent and widespread bone tissue injury after heating to $50^{\circ} \mathrm{C}$ for one minute [20].

In a cadaveric study of vertebroplasty without cement leakage, the temperature at the spinal canal did not exceed $41^{\circ} \mathrm{C}$ and there was no evidence of injury to neural structures [21]. The posterior cortex of the vertebra acts as an insulator between heated bone cement and neural structures. Toksvig-Larsen et al. [17] reported that only a moderate temperature elevation on the surface of the dural sac provided that the posterior cortex of the vertebra was retained together with $0.5 \mathrm{~cm}$ of the spongious bone. The dorsal wall acts as a temperature barrier and prevents a significant increase in the temperate of the epidural space during cement curing. Aeblia et al. [15] concluded that the spinal cord does not seem to be in danger of thermal injury during vertebroplasty as long as there is no epidural leakage.

In the present study, the amount of bone cement, the shape of cavity and the distance between bone cement and cortex were standardized. In the stage 1 experiment, in which bone cement was confined within the vertebra, temperatures at the anterior cortex, neural foramen, and posterior cortex did not rise above $45^{\circ} \mathrm{C}$. In the stage 2 experiment, in which bone cement leaked into the spinal canal, the peak average temperature of these areas was $59^{\circ} \mathrm{C}$ and the average temperature remained higher than $45^{\circ} \mathrm{C}$ for more than 5 minutes. The increase in temperature observed in this experiment shows that bone cement leaking into the spinal canal can potentially cause thermal injury to neural tissue. In addition to the commonly accepted concern that neural compression may occur due to space-occupying bone cement present in the spinal canal, the exothermic reaction of bone cement might result in neural tissue damage if there is direct contract between bone cement and neural tissue.

Leakage of bone cement during vertebroplasty will theoretically contribute to elevated temperatures at the anterior, foramen, posterior and center positions. Our data shows that the temperature differences observed in vertebroplasty with and without leakage are 0.3, 1.6, 19.1 and $9.2^{\circ} \mathrm{C}$ for the anterior, foramen, posterior and center positions respectively. The observed temperature difference is negligible at the anterior and foramen positions, significant at the posterior position and slightly different at the center position. Because the anterior and foramen positions were directly exposed to $37^{\circ} \mathrm{C}$ saline, the majority of the heat generated was transferred by convection through this medium. This resulted in the lack of significant temperature differences at the anterior and foramen positions. The posterior position was exposed to $37^{\circ} \mathrm{C}$ saline but concealed in the spinal canal; thus, heat dispersion at the posterior position was less efficient than at the anterior and foramen positions. Furthermore, the leaked bone cement directly contacted the thermocouple at the posterior position (and neural tissue in the clinical situation) causing significant temperature elevation. The center position was within the bulk of the bone cement and did not contact the saline solution; in this case, heat dispersion was by conduction through bone cement and bone instead of by convection through water. Heat accumulation caused a slight difference in temperature in vertebroplasties with and without leakage at the center position. Belkoff et al. [12] reported that internal temperature elevation in vertebroplasty caused osteonecrosis. Our study demonstrates that cement leakage into the spinal canal might cause neural thermal damage.

The obvious differences between clinical vertebroplasty and the in vitro porcine model point to several limitations of the present study. First, the specimens used are porcine vertebrae rather than human vertebrae. Second, vertebroplasty is simulated with man-made cavities instead of natural compression fractures. (However, the model in this study facilitated the amount and location of cement leakage.) Third, convective heat transfer due to blood perfusion was not accounted for in the current study but would be expected to reduce temperatures substantially in vivo. It is therefore possible that temperatures observed in this study overestimate the temperature changes that may occur in vivo. In turn, the heat convection effect of blood flow may not be as effective in the clinical situation because blood flow decreases with age [22]. Last, this study was conducted using disarticulated vertebrae instead of an en bloc spine. Temperature recordings from within the relevant soft tissues may have been more akin to in vivo temperatures. 


\section{Conclusions}

The results indicate that, for bone cement confined within vertebrae, curing temperatures of the cement typically used in vertebroplasty will not cause direct thermal injury to the nearby soft tissue. In case in which bone cement leaked into the spinal canal, the temperature at the posterior cortex was observed to rise to $59^{\circ} \mathrm{C}$ and to remain above $45^{\circ} \mathrm{C}$ for more than 5 minutes. Cement leakage into the spinal canal will potentially cause neural compression due to occupation of space by the cement as well as thermal injury due to the exothermicity of cement polymerization.

\section{Acknowledgements}

Many thanks to Ya-Ting Shih for preparing figures and sorting references.

\section{Author details}

'Department of Orthopaedic Surgery, Chang Gung Memorial Hospital, Chang Gung University School of Medicine, Taoyuan, Taiwan. ${ }^{2}$ Department of Chemical Engineering, National Tsing Hua University, Hsinchu, Taiwan. ${ }^{3}$ Graduate Institute of Medical Mechatronics, Department of Mechanical Engineering, Chang Gung University, Taoyuan, Taiwan.

\section{Authors' contributions}

PLL set up the protocol, organized ethics approval, carried out the study and drafted the manuscript. CLT participated in the design of the study, the interpretation of the results and the drafting of the manuscript. LHC participated in the design of the study and helped with the analysis of data. NYN participated in carrying out the study and reviewing references. All authors read and approved the final manuscript.

\section{Competing interests}

This study was supported by a financial grant from Chang Gung Memorial Hospital (CMRPG381301). The funding source did not have any influence on the investigation.

Received: 12 November 2010 Accepted: 26 May 2011 Published: 26 May 2011

\section{References}

1. Peh WC, Munk PL, Rashid F, Gilula LA, Peh WCG, Munk PL, Rashid F, Gilula LA: Percutaneous vertebral augmentation: vertebroplasty, kyphoplasty and skyphoplasty. Radiolo Clin North Am 2008, 46(3):611-635.

2. Denaro L, Longo UG, Denaro V: Vertebroplasty and kyphoplasty: reasons for concern? Orthop Clin North Am 2009, 40(4):465-471.

3. Einhorn TA: Vertebroplasty: an opportunity to do something really good for patients.[comment]. Spine 2000, 25(9):1051-1052.

4. Masala S, Mastrangeli R, Petrella MC, Massari F, Ursone A, Simonetti G: Percutaneous vertebroplasty in 1,253 levels: results and long-term effectiveness in a single centre. Eur radiol 2009, 19(1):165-171.

5. Bettencourt A, Calado A, Amaral J, Vale F, Rico J, Monteiro J, Lopes A, Pereira L, Castro M: In vitro release studies of methylmethacrylate liberation from acrylic cement powder. Int pharm 2000, 197(1-2):161-168.

6. Anselmetti GC, Zoarski G, Manca A, Masala S, Eminefendic H, Russo F, Regge D: Percutaneous vertebroplasty and bone cement leakage: clinical experience with a new high-viscosity bone cement and delivery system for vertebral augmentation in benign and malignant compression fractures. Cardiovasc Intervent Radiol 2008, 31(5):937-947.

7. Yang SC, Chen WJ, Yu SW, Tu YK, Kao YH, Chung KC: Revision strategies for complications and failure of vertebroplasties. Eur Spine J 2008, 17(7):982-988

8. Sabuncuoğlu H, Dinçer $D$, Güçlü $B$, Erdoğan $E$, Hatipoğlu HG, Ozdoğan $S$, Timurkaynak E: Intradural cement leakage: a rare complication of percutaneous vertebroplasty. Acta neurochir 2008, 150(8):811-815.

9. McArthur N, Kasperk C, Baier M, Tanner M, Gritzbach B, Schoierer O, Rothfischer W, Krohmer G, Hillmeier J, Kock HJ, Meeder PJ, Huber FX: 1150 kyphoplasties over 7 years: indications, techniques, and intraoperative complications. Orthopedics 2009, 32(2):90.

10. Wilkes RA, Mackinnon JG, Thomas WG: Neurological deterioration after cement injection into a vertebral body. J Bone Joint Surg Br 1994, 76(1):155.

11. Uchiyama S, Yashiro K, Takahashi H, Homma T: An experimental study of spinal cord evoked potentials and histologic changes following spinal cord heating. Spine 1989, 14(11):1215-1219.

12. Belkoff $\mathrm{S}$, Molloy S: Temperature measurement during polymerization of polymethylmethacrylate cement used for vertebroplasty. Spine 2003, 28(14):1555-1559.

13. Leeson MC, Lippitt SB: Thermal aspects of the use of polymethylmethacrylate in large metaphyseal defects in bone. A clinical review and laboratory study. Clin Orthop Relat Res 1993, 295:239-245.

14. Zhao F, Lu WW, Luk KD, Cheung KM, Wong CT, Leong JC, Yao KD: Surface treatment of injectable strontium-containing bioactive bone cement for vertebroplasty. J Biomed Mater Res B Appl Biomater 2004, 69(1):79-86.

15. Aebli N, Goss BG, Thorpe $P$, Williams $R$, Krebs J: In vivo temperature profile of intervertebral discs and vertebral endplates during vertebroplasty: an experimental study in sheep. Spine 2006, 31(15):1674-1678.

16. Turner TM, Urban RM, Singh K, Hall DJ, Renner SM, Lim TH, Tomlinson MJ, An HS: Vertebroplasty comparing injectable calcium phosphate cement compared with polymethylmethacrylate in a unique canine vertebral body large defect model. Spine J 2008, 8(3):482-487.

17. Toksvig-Larsen S, Johnsson R, Stromqvist B: Heat generation and heat protection in methylmethacrylate cementation of vertebral bodies. A cadaver study evaluating different clinical possibilities of dural protection from heat during cement curing. Eur Spine J 1995, 4(1):15-17.

18. De Vrind $\mathrm{H}$, Wondergem J, Haveman J: Hyperthermia-induced damage to rat sciatic nerve assessed in vivo with functional methods and with electrophysiology. J neurosci methods 1992, 45(3):165-174.

19. Berman AT, Reid JS, Yanicko DR Jr, Sih GC, Zimmerman MR: Thermally induced bone necrosis in rabbits. Relation to implant failure in humans. Clin Orthop Relat Res 1984, 186:284-292.

20. Eriksson RA, Albrektsson T, Magnusson B: Assessment of bone viability after heat trauma. A histological, histochemical and vital microscopic study in the rabbit. Scand j plast reconstr surg 1984, 18(3):261-268.

21. Deramond H, Wright N, Belkoff S: Temperature elevation caused by bone cement polymerization during vertebroplasty. Bone 1999, 25(2 Suppl):17S-21S.

22. Chen WT, Shih TT, Chen RC, Lo SY, Chou CT, Lee JM, Tu HY: Vertebral bone marrow perfusion evaluated with dynamic contrast-enhanced MR imaging: significance of aging and sex. Radiology 2001, 220(1):213-218.

\section{Pre-publication history}

The pre-publication history for this paper can be accessed here: http://www.biomedcentral.com/1471-2474/12/116/prepub

doi:10.1186/1471-2474-12-116

Cite this article as: Lai et al:: Cement leakage causes potential thermal injury in vertebroplasty. BMC Musculoskeletal Disorders 2011 12:116.

\section{Submit your next manuscript to BioMed Central and take full advantage of:}

- Convenient online submission

- Thorough peer review

- No space constraints or color figure charges

- Immediate publication on acceptance

- Inclusion in PubMed, CAS, Scopus and Google Scholar

- Research which is freely available for redistribution

Submit your manuscript at www.biomedcentral com/submit
C Biomed Central 